\title{
New beginnings and old concepts refined
}

The selection of articles for this November issue of The Journal of Laryngology \& Otology illustrates some of the exciting advances and latest developments in cutting-edge otolaryngological research.

Narrow band imaging has recently gathered support for the endoscopic evaluation and detection of benign laryngeal diseases, such as laryngeal papillomatosis, as well as the early detection of pre-cancerous and malignant lesions. ${ }^{1}$ In a prospective study evaluating narrow band imaging for malignant laryngopharyngeal squamous cell carcinomas (SCCs), Ni et al. report improved specificity and sensitivity of narrow band imaging compared with conventional white light imaging (specificity 85 per cent vs 67 per cent; sensitivity 95 per cent vs 74 per cent). ${ }^{2}$ More evidence is therefore emerging to support the widespread use of narrow band imaging within the clinical arena.

Although research on the efficacy of neuromuscular electrical stimulation for the treatment of voice disorders is still in its infancy, its use as an adjuvant treatment for muscle tension dysphonia is explored and reported here in a paper by Gorham-Rowan and Morris. ${ }^{3}$ The authors found that a short session of laryngeal neuromuscular electrical stimulation may be beneficial in reducing muscle fatigue for some individuals. Further investigation is warranted in order to determine the applicability of laryngeal neuromuscular electrical stimulation in voice therapy.

The human papilloma virus (HPV) and oropharyngeal squamous cell carcinoma story gathers further momentum in an elegant study by Dale et al. in this month's issue. ${ }^{4,5}$ The authors have identified longterm survival outcomes in patients undergoing primary surgery for oropharyngeal squamous cell carcinoma and defined HPV status. Following dual modality HPV testing, using p16 immunohistochemistry and in situ hybridisation for HPV DNA, 42 per cent of 107 surgically treated patients over a 10 -year period were found to have HPV-positive tumours. Patients with HPV-positive tumours were found to have a significantly higher disease-specific survival rate than those with HPV-negative tumours $(p=0.012)$. The significant association between survival and other clinicopathological variables, including HPV status, led the authors to recommend the publishing of HPV status alongside survival rates in oropharyngeal squamous cell carcinoma.

The 'one airway' hypothesis predicts that inflammation in the upper airways is linked to inflammation in the lower airways. In this issue, a paper by Nesic et al. found higher average oral and nasal nitric oxide levels in acute rhinitis patients (without concomitant asthma) compared with healthy subjects. ${ }^{6}$ The authors further demonstrate the reliability and applicability of the measurement of nasal nitric oxide levels by both aspiration and exhalation methods. In keeping with the 'one airway' hypothesis, the results suggest generalised airway inflammation, even in the absence of asthma.

Older treatment paradigms are also revisited in this issue. In a randomised, single-blind study by Hitchcock et al., the authors conclude that manual disinfection has equivalent microbiological efficacy and superior cost-effectiveness compared with immersion and automated processes for the high-level disinfection of flexible nasendoscopes. ${ }^{7}$ The authors propose that this may improve turnaround times in busy ENT clinics.

The evidence basis for adenoidectomy alone in the treatment of paediatric obstructive sleep apnoea (OSA) is further substantiated by a systematic review and meta-analysis in this month's issue by Reckley et $a l^{8}{ }^{8}$ This builds on previous work demonstrating the effectiveness of adenotonsillectomy in the treatment of paediatric OSA. ${ }^{9}$ Use of the T14 tool may further assist in the future evaluation of isolated adenoidectomy for the treatment of paediatric OSA. ${ }^{10}$

\section{JONATHAN FISHMAN ROBIN YOUNGS EDWARD FISHER MUSHEER HUSSAIN Senior Editors}

References

1 Adachi K, Umezaki T, Kiyohara H, Komune S. New technique for laryngomicrosurgery: narrow band imaging-assisted videolaryngomicrosurgery for laryngeal papillomatosis. J Laryngol Otol 2015;129(suppl 2):S74-6

2 Ni XG, Zhang QQ, Wang GQ. Narrow band imaging versus autofluorescence imaging for head and neck squamous cell carcinoma detection: a prospective study. J Laryngol Otol 2016; 130:1001-6

3 Gorham-Rowan M, Morris R. Exploring the effect of laryngeal neuromuscular electrical stimulation on voice. J Laryngol Otol 2016;130: $1022-32$

4 Dale OT, Sood S, Shah KA, Han C, Rapozo D, Mehanna H et al. Long-term survival outcomes in patients with surgically treated oropharyngeal cancer and defined human papilloma virus status. J Laryngol Otol 2016;130:1048-53

5 Park E, Jung KY, Kwon SY, Woo JS, Cho JG, Park MW et al. Prognostic significance of tumour progression and human papillomavirus in advanced tonsillar cancer classified as stage IVa. J Laryngol Otol 2015;129:86-92 
6 Nesic VS, Djordjevic VZ, Tomic-Spiric V, Dudvarski ZR, Soldatovic IA, Arsovic NA. Measuring nasal nitric oxide in allergic rhinitis patients. J Laryngol Otol 2016;130:1064-71

7 Hitchcock B, Moynan S, Frampton C, Reuther R, Gilling P, Rowe F. A randomised, single-blind comparison of high-level disinfectants for flexible nasendoscopes. J Laryngol Otol 2016;130:983-9

8 Reckley LK, Song SA, Chang ET, Cable BB, Certal V, Camacho M. Adenoidectomy can improve obstructive sleep apnoea in young children: systematic review and meta-analysis. J Laryngol Otol 2016;130:990-4

9 Marcus CL, Moore RH, Rosen CL, Giordani B, Garetz SL, Taylor HG et al. A randomized trial of adenotonsillectomy for childhood sleep apnea. $N$ Engl J Med 2013;368:2366-76

10 Hopkins C, Almeyda R, Alreefy H, Ismail-Koch H, Lim J, Possamai V et al. Multicentre prospective clinical application of the T14 paediatric outcome tool. J Laryngol Otol 2015; 129:980-5 